\title{
Paradoxic hypertrophy of the sciatic nerve
}

\author{
Mingming Ma $\cdot$ R. Paul Guillerman
}

Received: 31 July 2010 / Accepted: 24 September 2010/Published online: 10 October 2010

(C) Springer-Verlag 2010

An asymptomatic 14-year-old boy with a right, above-knee amputation for osteosarcoma underwent a surveillance MRI of the lower extremities. It revealed an elliptical tubular structure of high signal intensity compared to muscle on

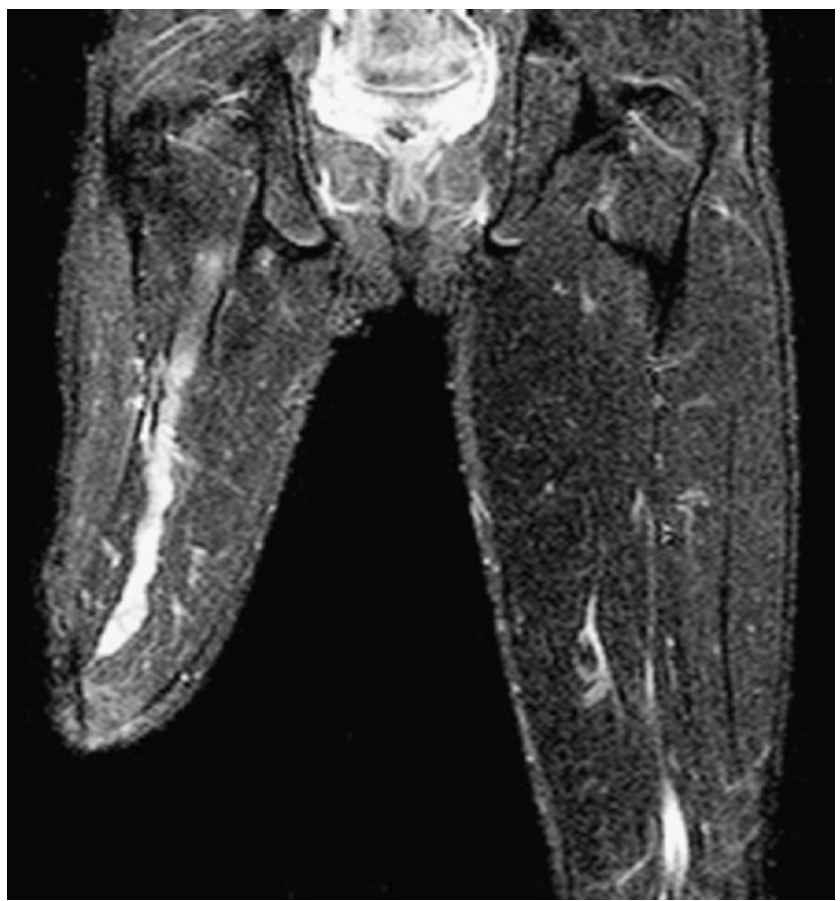

Fig. 1 Coronal STIR image

R. P. Guillerman $(\bowtie)$

Department of Radiology, Baylor College of Medicine,

Texas Children's Hospital,

6621 Fannin St., MC 2-2521,

Houston, TX 77030, USA

e-mail: rpguille@texaschildrens.org

M. Ma

Baylor College of Medicine,

Houston, TX, USA

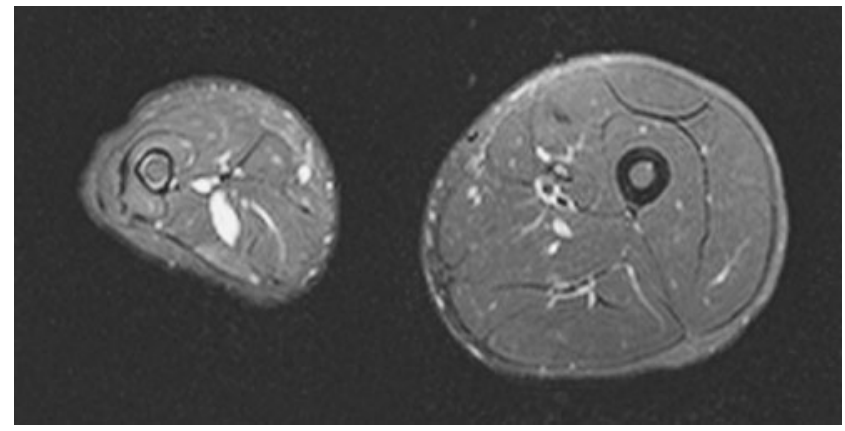

Fig. 2 Axial fat-saturated T2-W image

coronal STIR (Fig. 1) and axial fat-saturated T2-W (Fig. 2) images along the medial right thigh, representing a hypertrophied sciatic nerve.

Paradoxic sciatic nerve hypertrophy has been reported following lower limb amputation for malignant [1] and nonmalignant [2] conditions. Nerve hypertrophy is greatest near the transection site and extends proximally. It is termed paradoxical because proximal nerve atrophy usually ensues after transection [1]. Larger nerve diameters are associated with higher amputation level and longer duration after surgery, but not with pain complaints. The etiology is unclear and may involve dysregulated axonal neurofilament transport [1, 2]. Appropriate distinction of this benign process from a residual or locally recurrent tumor averts an unnecessary biopsy.

\section{References}

1. Hill SC, Baker AR, Barton NW et al (1997) Sciatic nerve: paradoxic hypertrophy after amputation in young patients. Radiology 205:559-562

2. Goktepe AS, Ozcakar L, Komurcu E et al (2010) Sonographic evaluation of the sciatic nerve in patients with lower-limb amputations. Muscle Nerve 41:763-766 